\title{
A corrupção na administração pública: Uma análise das publicações científicas
}

\section{internacionais}

\author{
Corruption in public administration: An analysis of international scientific publications \\ Corrupción en la administración pública: Un análisis de publicaciones científicas internacionale
}

Recebido: 04/05/2021 | Revisado: 09/05/2021 | Aceito: 13/05/2021 | Publicado: 30/05/2021

\author{
Marcelo Matzenbacher Delanoy \\ ORCID: https://orcid.org/0000-0002-1658-3066 \\ Universidade Federal do Pampa, Brasil \\ E-mail: marcelodelanoy@gmail.com \\ Rafael Rudolfo Kreutz \\ ORCID: https://orcid.org/0000-0001-5618-0459 \\ Universidade Estadual do Rio Grande do Sul, Brasil \\ E-mail: rafael.kreut@gmail.com \\ Kelmara Mendes Vieira \\ ORCID: https://orcid.org/0000-0002-8847-0941 \\ Universidade Federal de Santa Maria, Brasil \\ E-mail: kelmara@terra.com.br
}

\begin{abstract}
Resumo
O estudo procura identificar o panorama das publicações sobre corrupção na administração pública na literatura internacional nas últimas duas décadas. Para a análise dos dados utilizou-se a base de dados do Scopus e uma mescla das técnicas de bibliometria, análise de conteúdo, análise das redes e nuvem de palavras. Para tanto, essa pesquisa é delineada como descritiva, de análise bibliométrica e quantitativa. Foram encontrados 311 artigos com os EUA apresentando uma representação mais expressiva na produção internacional com $21,1 \%$ dos artigos, seguido por Austrália (8,6\%) e Reino Unido (6,1\%). Já o Brasil aparece em $24^{\circ}$ lugar com apenas 4 (1,2\%) publicações. Os resultados demonstraram que a International Journal Of Public Administration e a Public Administration And Development, com 15 artigos publicados cada uma, seguido pela Public Administration Review, com 14, e a Mediterranean Journal of Social Sciences, com 10, foram os principais periódicos em número de publicações sobre corrupção na administração pública. Ainda, foram identificados somente cinco clusters com cinco ou mais ligações de coautoria em pesquisa, indicando que há um baixo índice de desenvolvimento de pesquisas em cooperação. Além disso, os dados parecem evidenciar que a literatura mundial acerca da temática se encontra relativamente consolidada, diferentemente da nacional, que ainda necessita de maiores avanços.
\end{abstract}

Palavras-chave: Corrupção; Setor público; Publicações cientificas; Bibliometria.

\begin{abstract}
The study seeks to identify the panorama of public administration corruption publications in the international literature over the past two decades. For data analysis we used Scopus database and a mixture of bibliometrics, content analysis, network analysis and word cloud techniques. Therefore, this research is delineated as descriptive, bibliometric and quantitative analysis. A total of 311 articles were found in the US with a more significant representation in international production with $21.1 \%$ of articles, followed by Australia (8.6\%) and the United Kingdom (6.1\%). Already Brazil appears in 24th place with only $4(1.2 \%)$ publications. The results showed that the International Journal of Public Administration and Public Administration and Development, with 15 articles each, followed by the Public Administration Review, 14, and the Mediterranean Journal of Social Sciences, 10, were the top journals in number. publications on corruption in the public administration. Also, only five clusters with five or more co-authoring research links were identified, indicating that there is a low rate of cooperative research development. Moreover, the data seem to show that the world literature on the subject is relatively consolidated, unlike the national literature, which still needs further advances.
\end{abstract}

Keywords: Corruption; Public sector; Scientific publications; Bibliometry.

\section{Resumen}

El estudio busca identificar el panorama de las publicaciones sobre corrupción en la administración pública en la literatura internacional en las últimas dos décadas. Para el análisis de datos se utilizó la base de datos Scopus y una combinación de bibliometría, análisis de contenido, análisis de redes y técnicas de nube de palabras. Por tanto, esta investigación está diseñada como análisis descriptivo, bibliométrico y cuantitativo. Se encontraron 311 artículos con EUA. mostrando una representación más expresiva en la producción internacional con el 21,1\% de los artículos, seguido de Australia (8,6\%) y Reino Unido (6,1\%). 
Brasil aparece en el lugar 24 con solo 4 (1,2\%) publicaciones. Los resultados mostraron que la Revista Internacional de Administración Pública y Administración Pública y Desarrollo, con 15 artículos publicados cada uno, seguida de la Revista de la Administración Pública, con 14, y la Revista Mediterránea de Ciencias Sociales, con 10, fueron las principales revistas en número de publicaciones sobre corrupción en la administración pública. Además, solo se identificaron cinco conglomerados con cinco o más enlaces de coautoría en la investigación, lo que indica que existe una baja tasa de desarrollo de la investigación en cooperación. Además, los datos parecen mostrar que la literatura mundial sobre el tema está relativamente consolidada, a diferencia de la nacional, que aún necesita más avances.

Palabras clave: Corrupción; Sector público; Publicaciones cientificas; Bibliometría.

\section{Introdução}

$\mathrm{Na}$ atualidade a corrupção tem se destacado como algo presente em todos os países, independentemente do sistema político, econômico ou legal, porém, tem se apresentado em diferentes níveis e maneiras, intensidades e escalas (Brol, 2016). A corrupção é vista como um problema comportamental com consequência diversas (Luciano, Wiedenhöft, Callegaro, 2019) e pode ser considerada um dos principais fatores que limitam o crescimento econômico de um país. Ela está amplamente distribuída nos mais diferentes segmentos da sociedade, em diversos países. Dados do Banco Mundial estimam que o custo da corrupção equivale a mais de 5\% do PIB mundial (2,6 trilhões de dólares), com o pagamento de cerca de 1 trilhão de dólares em propinas por ano (Ribeiro, Alves, Martins, 2018).

Existem abordagens distintas sobre corrução na literatura, que são destacadas em diversas dimensões de estudos, em especial a legal, econômica, política, cultural e administrativa, as quais trazem diferentes entendimentos sobre quais são as causas da corrupção e quais possíveis maneiras de reduzir a sua ocorrência ou intensidade (Luciano, Magnagnagno, Wiedenhöft, 2017). Quanto às definições, Brei (1996) equivale corrupção à trapaça, ganho ilícito, fraude e suborno, entre outros. Sims, Gong e Ruppel (2012) incluem na definição de corrupção "propinas, coerção e atividades relacionadas que proporcionam uma vantagem injusta a uma parte". Já a organização Transparency International (2018) define a corrupção como “Abuso de cargo público para ganhos privados". A corrupção é um tema bastante discutido, no entanto, ainda é considerado como insuficientemente pesquisado (Srivastava, Teo, Devaraj, 2016). Um dos principais motivos para a falta de atenção acadêmica e de pesquisa dada à corrupção é a sua presença constante e dissimulada nas rotinas de trabalho do governo (Herzfeld, Weiss, 2003). Além disso, apesar dos administradores públicos e os governos perceberem as sequelas deixadas pela corrupção, normalmente o seu combate não é objeto de preocupação imediata (Srivastava, Teo, Devaraj, 2016).

Realizar um levantamento de literatura através da pesquisa de publicações sobre uma temática é uma forma de avaliar e interpretar quais são as pesquisas disponíveis mais relevantes em uma área ou fenômeno de interesse (Kitchenham, 2004), neste estudo utilizou-se a técnica bibliometria. O uso de técnicas bibliométricas auxiliam no entendimento de novas temáticas, e por consequência podem ajudar na identificação de tendências para pesquisas futuras, identificando lacunas e oportunidades no campo do saber estudado (Quevedo-Silva, Santos, Brandão,2016). Ademais, realizar uma análise dos principais periódicos que desenvolvem pesquisa sobre o tema possibilita encontrar de onde as pesquisas sobre corrupção tem mais destaques, bem como informações sobre os principais pesquisadores do tema (Schlickmann, Bortoluzzi, 2020). Assim, a pesquisa está centrada em realizar uma análise do panorama de publicações sobre a corrupção na administração pública nas últimas duas décadas. Pretendeu-se verificar qual nível o de publicações internacionais e identificar quais os principais autores, países e instituições que tem se destacado, pretende-se contribuir com o estudo do tema à medida que procura compreender e direcionar quais são os principais temas abordadas nos estudos voltados corrupção na administração pública em nível internacional.

\section{Corrupção: Conceitos e Classificações}

Definir o termo corrupção tem sido um desafio para os estudiosos da área, pois o termo abarca muitos sinônimos na sua utilização cotidiana. A grande variedade de significados e também a amplitude do próprio ato de corrupção dificultam o processo 
de conceituação. Brei (1996) equivale corrupção à trapaça, velhacaria, logro, ganho ilícito, desfalque, concussão, falsificação, espólio, fraude, suborno, peculato, extorsão e nepotismo, entre outros. Sims, Gong e Ruppel, (2012) incluem na definição de corrupção "propinas, coerção e atividades relacionadas que proporcionam uma vantagem injusta a uma parte". A organização Transparency International (2018) define a corrupção como “Abuso de cargo público para ganhos privados”. Essa variedade de significados demonstra a dificuldade em conceituar o termo. Quanto à sua classificação, Brei (1996) propõe três dimensões: grande, pequena e política. Na visão de Nobre e Cotomacci (2020), o exercício da corrupção afeta todo o desempenho da função pública bem como também o desenvolvimento da atividade administrativa. A prática da corrupção percorre desde um pequeno desvio de conduta até a formação de imensas organizações criminosas, atuando em diversas áreas e níveis governamentais. Para xxx Essa amplitude abrange desde a compra da agilidade de um simples processo burocrático até a obtenção de benefícios ilegais. Como ratificação de sua amplitude, ações de natureza tão distintas resultam em consequências e penas igualmente diferentes.

Em outra classificação distingue-se os componentes da corrupção política e os tipos de corrupção. Os componentes da corrupção política incluem conceitos que definem um ato corrupto. Já os tipos de corrupção são constituídos de subconceitos como clientelismo, compra de votos, curral eleitoral ou apadrinhamento, suborno, extorsão, conflito de interesses, nepotismo, tráfico de influência e campanha financeira corrupta para fundos eleitorais. Ainda, a corrupção pode estar relacionada às seguintes dimensões: i) grau do envolvimento, ii) status dos atores envolvidos, iii) tipos de recompensas oferecidas, iv) a seletividade dos incentivos, v) local ou área da atividade; e por fim, vi) o nível de condenação (Peters, Welch, 1978). Já em termos de causa e consequência, Treisman (2000) relata a dificuldade de um estudo empírico sobre corrupção, pois suas causas se inter-relacionam de muitas formas distintas, por exemplo: um ato que pode ter sido causado por corrupção, em outro momento se torna sua causa, tornando a definição "abuso de cargo público para ganho privado" excessivamente simples para conceituar o termo corrupção.

Sob o ponto de vista jurídico, os dispositivos legais trazem em seu corpo a definição de corrupção. No Brasil, o Congresso Nacional decretou a Lei Anticorrupção - lei no 12.846, sancionada em $1^{\circ}$ de agosto de 2013 - criada com vistas à responsabilização administrativa e civil de pessoas jurídicas pela prática de atos contra a administração pública. A norma ainda traz a responsabilização administrativa e cível das pessoas jurídicas pelos atos ilícitos que lhes favorecem. Desta forma, existem dois requisitos para a aplicação da Lei: o dano ao erário público, nacional ou estrangeiro e a conduta ilegal de uma pessoa jurídica.

\section{Corrupção no Brasil e no Mundo}

O caso Watergate, ocorrido em 1977 nos Estados Unidos, que provocou a renúncia do presidente Richard Nixon, é considerado um caso clássico quando se estuda a corrupção. Após esse escândalo, Susan Rose-Ackerman publicou em 1978 o estudo Corruption: a study in political economy em que argumenta que o papel e o impacto da corrupção sobre a economia e as organizações políticas são mais extensos e profundos do que até então se sustentava, sendo considerado um divisor de águas (Abramo, 2005). Casos recentes como a acusação de roubo de aproximadamente 150 milhões de dólares pelos dirigentes da Federação Internacional de Futebol (FIFA), demonstram que a corrupção pode estar nas mais diversas relações políticas. O resultado desse cenário, é a prisão de diversos dirigentes da federação por parte da polícia suíça. Em decorrência deste fato, o FBI liderou uma investigação a executivos e funcionários da federação.

O Escritório das Nações Unidas contra Drogas e Crime (UNODC), relata que a corrupção começou a ser tema de interesse dos mais diferentes países, embora os primeiros acordos de ação conjunta tenham ocorrido em âmbito regional, alguns com abordagens específicas, como o suborno, por exemplo. As primeiras convenções firmadas não cobriam todas as regiões do mundo, deixando de lado alguns países da Ásia e do Oriente Médio. A comunidade internacional, preocupada com o tema e com a necessidade de produzir um arranjo global capaz de prevenir e combater a corrupção estabeleceu a Convenção das Nações 
Unidas contra a Corrupção. Deste encontro surgiu o documento intitulado Convenção das Nações Unidas Contra a Corrupção (2007) o qual enfatizou que a corrupção deixou de ser um problema local para converter-se em um fenômeno transnacional que afeta todas as sociedades e economias, e, portanto, faz-se necessária a cooperação internacional para preveni-la e lutar contra ela (Nações Unidas, 2007).

Zaganelli e Miranda (2017) afirmam que manifestações, impeachment, mensalão, lava-jato são palavras que atualmente remetem à corrupção. No Brasil, o principal caso em evidência é a Operação Lava-jato, que investiga desvio de dinheiro e demissões em massa na empresa estatal petrolífera brasileira Petrobrás entre 2004 e 2012 por parte de políticos e empreiteiras. O evento ganhou tanta repercussão que contribuiu para o alargamento da crise econômica do país. Esses fatos provocam debates acerca de medidas que possam combater o mau uso dos recursos públicos. A Controladoria Geral da União (CGU), órgão criado com o propósito de combater a corrupção e incrementar a transparência no Brasil, afirma que o fenômeno da corrupção não afeta somente governos, mas, também, cidadãos, entidades públicas e instituições privadas, provocando a concorrência desleal, comprometendo o crescimento econômico e afastando novos investimentos. A redução dos níveis de corrupção no país é um tema fundamental tanto para fortalecer as instituições democráticas quanto para viabilizar o crescimento econômico. (Controladoria Geral da União, 2009). Para De Oliveira Costa, Cunha, Bezerra, De Oliveira, Do Vale Júnior \& Junior (2020), uma forma para combater a corrupção que assombra o Brasil é através do fortalecimento dos Tribunais de Contas por meio de uma nova cultura institucional.

\section{Medidas de Corrupção}

Encontrar uma métrica para a corrupção tem sido objeto de esforços acadêmicos. Medidas diretas sobre práticas de corrupção não são facilmente mensuradas, o que dificulta evidências empíricas e isso decorre do fato de que atos de corrupção são secretos. Portanto, as medidas indiretas dominam as análises a respeito da corrupção. Dentre as principais formas, verificase que o índice de percepções de corrupção tem sido amplamente utilizado, e que, por enquanto, o mais próximo que se chega na avaliação da corrupção parte de levantamentos sobre a percepção de sua presença. A principal crítica a respeito do índice está no fato de que é decorrente de opiniões, podendo as notícias veiculadas nos meios de comunicação influenciar as opiniões formadoras do índice, alterando, assim, o resultado. Nesse sentido, se de um lado o aumento da divulgação de casos de corrupção pode ser interpretado como consequente aumento dos atos de corrupção, por outro, o aumento dessas notícias, podem representar melhorias nos mecanismos de controle (Abramo, 2000, 2005)

É preciso considerar também que as pessoas percebem a corrupção diferentemente (Brei, 1996). As reações à corrupção ou sua tolerância podem envolver crenças e sentimentos individuais e que resultam da subjetividade envolvida no sentimento de cada um (Dolan, Mckeown,Carlson, 1988). As principais pesquisas sobre a corrupção são realizadas por meio de entrevistas nas quais os respondentes relatam a sua percepção a respeito do tema. É comum que executivos ou jornalistas sejam questionados sobre a incidência de práticas corruptivas em determinados países. Outras pesquisas sobre a percepção da corrupção derivam de entrevistas feitas internamente em países e as amostragens variam do meio empresarial à população em geral. A ONG Transparency International (TI) é uma das instituições mais conhecidas que realiza estudos sobre o tema (Abramo, 2000). O estudo bibliométrico de Nascimento (2016), identificou que 38\% dos artigos utilizaram diretamente o Corruption Perceptions Index (CPI) elaborado pela TI, ou o citaram indiretamente, confirmando a posição do CPI como índice mais utilizado atualmente.

O índice CPI é elaborado a partir de uma combinação de pesquisas e avaliações realizadas por organizações como o Banco Mundial, o Banco Governamental de Desenvolvimento Africano, a Fundação Bertelsmann Stiftung e o jornal The Economist, entre outros. Após a combinação de diversas pesquisas, é dado um tratamento estatístico que determina o índice de percepção de corrupção para cada país mencionado em três ou mais levantamentos. O conjunto de todos os países compõe o Índice de Percepções de Corrupção da Transparência Internacional, denominado no Brasil de IPCorr. No ano de 1999, o índice 
incluía 99 países. Na última publicação, o índice abrangeu as percepções de corrupção no setor público em 180 países. O quadro a seguir destaca os índices internacionais que compõem o CPI/IPCorr.

Quadro 1 - Descrição dos índices de corrupção.

\begin{tabular}{|c|c|c|c|c|c|}
\hline Índice & Fonte & $\begin{array}{c}\text { Países } \\
\text { envolvidos }\end{array}$ & Países & Tipo de avaliação & $\begin{array}{c}\text { Dimensões } \\
\text { analisadas }\end{array}$ \\
\hline $\begin{array}{l}\text { Country Policy and } \\
\text { Institutional } \\
\text { Assessment (2016) }\end{array}$ & $\begin{array}{c}\text { African } \\
\text { Development } \\
\text { Bank }\end{array}$ & Países africanos & 54 & $\begin{array}{c}\text { Avaliação de } \\
\text { especialistas através de } \\
\text { questionário }\end{array}$ & $\begin{array}{c}\text { Transparência, } \\
\text { prestação de } \\
\text { contas, corrupção no } \\
\text { setor público } \\
\end{array}$ \\
\hline $\begin{array}{l}\text { Sustainable } \\
\text { Governance } \\
\text { Indicators (2017) }\end{array}$ & $\begin{array}{l}\text { Bertelsmann } \\
\text { Stiftung }\end{array}$ & $\begin{array}{l}\text { União europeia } \\
\text { e OECD } \\
\text { (Organisation } \\
\text { for Economic } \\
\text { Co-operation } \\
\text { and } \\
\text { Development) }\end{array}$ & 41 & $\begin{array}{c}\text { Combinação de dados } \\
\text { quantitativos e avaliações } \\
\text { qualitativas de } \\
\text { especialistas através de } \\
\text { questionário }\end{array}$ & $\begin{array}{l}\text { Prevenção à } \\
\text { corrupção }\end{array}$ \\
\hline $\begin{array}{l}\text { Transformation } \\
\text { Index (2017-2018) }\end{array}$ & $\begin{array}{l}\text { Bertelsmann } \\
\text { Stiftung }\end{array}$ & $\begin{array}{c}\text { Excluidos os } \\
\text { membros da } \\
\text { OECD }\end{array}$ & 129 & $\begin{array}{c}\text { Avaliação de } \\
\text { especialistas através de } \\
\text { questionário }\end{array}$ & $\begin{array}{c}\text { Capacidade do } \\
\text { governo de combater a } \\
\text { corrupção }\end{array}$ \\
\hline $\begin{array}{l}\text { Country Risk } \\
\text { Service (2017) }\end{array}$ & $\begin{array}{c}\text { Economist } \\
\text { Intelligence Unit }\end{array}$ & $\begin{array}{c}\text { Países e } \\
\text { territórios de } \\
\text { todo o mundo }\end{array}$ & 131 & $\begin{array}{l}\text { Avaliações de } \\
\text { risco baseadas } \\
\text { em indicadores } \\
\text { qualitativos e } \\
\text { quantitativos }\end{array}$ & $\begin{array}{c}\text { O uso dos recursos } \\
\text { públicos }\end{array}$ \\
\hline $\begin{array}{l}\text { Nations in Transit } \\
(2017)\end{array}$ & Freedom House & $\begin{array}{c}\text { Europa central e } \\
\text { Asia central }\end{array}$ & 29 & $\begin{array}{c}\text { Avaliação de } \\
\text { especialistas através de } \\
\text { questionário }\end{array}$ & $\begin{array}{c}\text { Progresso e } \\
\text { contratempos para a } \\
\text { democratização } \\
\end{array}$ \\
\hline $\begin{array}{l}\text { Business } \\
\text { Conditions and Risk } \\
\text { Indicators (2016) }\end{array}$ & $\begin{array}{l}\text { IHS Global } \\
\text { Insight Global } \\
\text { Risk Service }\end{array}$ & $\begin{array}{c}\text { Países e } \\
\text { territórios de } \\
\text { todo o mundo }\end{array}$ & 204 & $\begin{array}{c}\text { Avaliação de } \\
\text { especialistas em } \\
\text { Comércio e Negócios }\end{array}$ & $\begin{array}{l}\text { Avaliação de risco } \\
\text { operacional }\end{array}$ \\
\hline $\begin{array}{l}\text { IMD World } \\
\text { Competitiveness } \\
\text { Yearbook (2017) } \\
\end{array}$ & \begin{tabular}{|c|} 
IMD World \\
Competitiveness \\
Center \\
\end{tabular} & $\begin{array}{c}\text { Países e } \\
\text { territórios de } \\
\text { todo o mundo } \\
\end{array}$ & 63 & $\begin{array}{c}\text { Pesquisa de opinião com } \\
\text { executivos através de } \\
\text { questionário }\end{array}$ & $\begin{array}{l}\text { Suborno e corrupção: } \\
\text { existe ou não existe. }\end{array}$ \\
\hline $\begin{array}{l}\text { Political and } \\
\text { Economic Risk } \\
\text { Consultancy (2017) } \\
\end{array}$ & $\begin{array}{c}\text { Political and } \\
\text { Economic Risk } \\
\text { Consultancy }\end{array}$ & $\begin{array}{c}\text { Países da Ásia, } \\
\text { Pacífico, }+ \\
\text { EUA }\end{array}$ & 15 & $\begin{array}{c}\text { Pesquisa de opinião com } \\
\text { executivos através de } \\
\text { questionário }\end{array}$ & Corrupção \\
\hline $\begin{array}{l}\text { The PRS Group } \\
\text { International } \\
\text { Country Risk Guide } \\
(2017)\end{array}$ & PRS Group & $\begin{array}{c}\text { Países e } \\
\text { territórios de } \\
\text { todo o mundo }\end{array}$ & 140 & Avaliação de risco & $\begin{array}{l}\text { Avaliações de risco } \\
\text { político }\end{array}$ \\
\hline $\begin{array}{l}\text { World Bank } \\
\text { Country Policy and } \\
\text { Institutional } \\
\text { Assessment ((2017) }\end{array}$ & World Bank & $\begin{array}{c}\text { Membros da } \\
\text { AID }\end{array}$ & 95 & $\begin{array}{l}\text { Avaliações de } \\
\text { especialistas }\end{array}$ & $\begin{array}{c}\text { Transparência, } \\
\text { accountability e } \\
\text { corrupção no setor } \\
\text { público. }\end{array}$ \\
\hline $\begin{array}{l}\text { World Economic } \\
\text { Forum Executive } \\
\text { Opinion Survey } \\
(2017)\end{array}$ & $\begin{array}{l}\text { World Economic } \\
\text { Forum }\end{array}$ & $\begin{array}{c}\text { Participantes do } \\
\text { Forum } \\
\text { Econômico } \\
\text { Mundial } \\
\end{array}$ & 133 & $\begin{array}{c}\text { Pesquisa de opinião com } \\
\text { executivos através de } \\
\text { questionário }\end{array}$ & Corrupção \\
\hline $\begin{array}{l}\text { World Justice } \\
\text { Project Rule of Law } \\
\text { Index (2017-2018) }\end{array}$ & $\begin{array}{l}\text { World Justice } \\
\text { ProjectA13 }\end{array}$ & \begin{tabular}{|c|} 
Países com \\
diversidade em \\
sistemas social, \\
cultural, \\
econômica e \\
político. \\
\end{tabular} & 113 & $\begin{array}{c}\text { Avaliação de } \\
\text { especialistas através de } \\
\text { questionário }\end{array}$ & $\begin{array}{l}\text { Uso do órgão público } \\
\text { para ganhos privados. }\end{array}$ \\
\hline $\begin{array}{l}\text { Varieties of } \\
\text { Democracy Project } \\
(2017)\end{array}$ & \begin{tabular}{|} 
University of \\
Gothenburg, V- \\
Dem Institute \\
and University of \\
Notre Dame
\end{tabular} & $\begin{array}{c}\text { Países e } \\
\text { territórios de } \\
\text { todo o mundo }\end{array}$ & 177 & $\begin{array}{c}\text { Avaliação de } \\
\text { especialistas através de } \\
\text { questionário }\end{array}$ & Corrupção \\
\hline
\end{tabular}

Fonte: Autores. 
A maior parte dos índices utiliza como metodologia a obtenção de opinião de especialistas através de questionários. No entanto, as instituições Economist Intelligence Unit e PRS Group utilizam-se de um tipo de avaliação diferente das demais, pois a abordagem empregada é a avaliação de riscos e não a técnica de aplicação de questionários. A dimensão mais analisada nos índices é a corrupção, sendo que em algumas instituições o foco de análise é mais específico, como por exemplo, prestação de contas ou suborno. A abrangência dos índices é restrita à área de atuação da organização responsável pela sua elaboração.

\section{Metodologia}

Quanto aos objetivos, a pesquisa pode ser considerada como descritiva, pois tem a pretensão de verificar qual a situação da produção científica sobre corrupção na administração pública em periódicos internacionais no período de 1997 a 2017. Para isso, foram utilizadas técnicas padronizadas de coleta de dados que possibilitam a observação, o registro e análise sem interferência do pesquisador sobre os mesmos (Prodanov, Freitas, 2013). Quanto à abordagem do problema, optou-se por utilizar um enfoque predominantemente quantitativo.

O estudo foi desenvolvido através de uma mescla das técnicas de bibliometria, nuvem de palavras, análise das redes e análise de conteúdo. A bibliometria é utilizada como uma técnica para o mapeamento dos principais autores, periódicos e palavras-chave sobre determinado tema (Bräscher, Café, 2008; Ferenhof, Vignochi, Selig, 2014), ou seja, é possível realizar uma observação da evolução da literatura sobre o assunto no decorrer dos anos (Araújo, Freire, Autran, 2000). A segunda técnica utilizada foi o método de nuvem de palavras, elaborada com o auxílio do Word Art, com a intenção de verificar os temas mais abordados pelos artigos mais citados na literatura. Em seguida realizou-se a análise das redes com a utilização do software VOSviewer.

Por fim, para a última técnica de análise realizou-se a seleção dos artigos mais relevantes com o objetivo de fazer uma análise de seu conteúdo através da identificação do objetivo, objeto de estudo e resultados. Dessa forma, optou-se pela escolha dos dez artigos mais citados, uma vez que os mesmos podem ser considerados como os mais representativos para a literatura. Para desenvolvimento dessa etapa utilizou-se a técnica de análise de conteúdo, segundo Vergara (2005), essa técnica visa identificar o que está sendo dito a respeito de determinado tema.

No que se refere à coleta de dados, este estudo optou por utilizar a base de dados do Scopus, que a Elsevier (2018) destaca como sendo a maior base de dados de produções científicas internacionais em periódicos, livros e anais de conferências. Ainda, segundo Elsevier (2011), a "Scopus permite uma visão ampla de tudo que está sendo publicado cientificamente sobre um tema, permitindo que se tenha uma quantidade de informações suficientes para basear seus projetos". Esse processo de busca foi desenvolvido durante o mês de março de 2018. Para a busca utilizou-se as palavras-chave de busca "Public Administration AND Corruption", as quais deveriam constar no título, resumo ou palavras-chave dos artigos, objetivando-se abranger os artigos que tratam da temática corrupção aliada às discussões sobre o setor público.

Além disso, utilizou-se o filtro para restringir os trabalhos acadêmicos, optando-se apenas por "Article" e estabeleceuse uma restrição temporal de 1997 a 2017. Ainda, foram aplicados filtros para restringir as publicações da área de Ciências Sociais e Humanas e posteriormente as subáreas de gestão, a saber, "Social Sciences e Business, Management e Accounting". Utilizou-se as ferramentas de tabulação que eram ofertadas pela própria base de dados do Scopus. No Quadro 2 apresenta-se um resumo sobre as etapas de construção da pesquisa que foram utilizadas, a fim de possibilitar o alcance dos objetivos propostos. 
Quadro 2 - Resumo das etapas da construção metodológica da pesquisa.

\begin{tabular}{|c|c|c|}
\hline \multirow{15}{*}{ 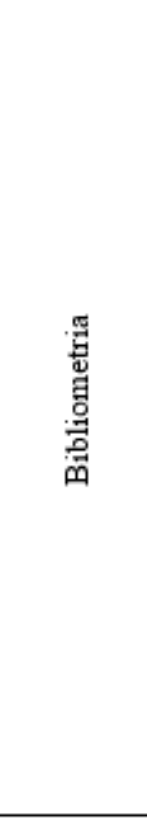 } & \multirow{3}{*}{$\begin{array}{c}\text { Seleção do Objeto de } \\
\text { pesquisa e da base } \\
\text { científica }\end{array}$} & a) definir o campo científico e teórico do trabalho; \\
\hline & & b) delimitar os objetivos do trabalho; \\
\hline & & c) escolher a base cientifica que será realizada a busca dos artigos. \\
\hline & \multirow{3}{*}{$\begin{array}{l}\text { Procedimentos de } \\
\text { Busca de dados }\end{array}$} & a) definir a base de dados de busca; \\
\hline & & b) definir os operadores para uma pesquisa avançada; \\
\hline & & c) definir os filtros de busca. \\
\hline & \multirow{3}{*}{$\begin{array}{l}\text { Coleta e organização } \\
\text { dos dados }\end{array}$} & a) definir o software de análise bibliométrica; \\
\hline & & $\begin{array}{l}\text { b) realizar o download das referências no formado do software de análise } \\
\text { bibliométrica e no formato de planilha eletrônica; }\end{array}$ \\
\hline & & c) importar os arquivos para o software de análise bibliométrica. \\
\hline & \multirow{6}{*}{$\begin{array}{l}\text { Análise quantitativa } \\
\text { das produções } \\
\text { científicas da amostra }\end{array}$} & a) análise do volume temporal dos artigos; \\
\hline & & b) análise de citações dos artigos mais relevantes; \\
\hline & & c) análise dos periódicos que mais publicaram; \\
\hline & & d) análise dos autores que mais produziram; \\
\hline & & e) análise das Publicações por instituições de filiação; \\
\hline & & f) análise dos Países que mais se destacaram em publicações; \\
\hline $\begin{array}{c}\text { Nuvem } \\
\text { palavras }\end{array}$ & Nuvem de Palavras & $\begin{array}{l}\text { a) análise dos temas centrais através das palavras mais abordadas nas } \\
\text { pesquisas. }\end{array}$ \\
\hline \multirow{3}{*}{$\begin{array}{l}\text { Análise } \\
\text { das } \\
\text { Redes }\end{array}$} & \multirow{3}{*}{$\begin{array}{l}\text { Análise de redes de } \\
\text { colaboração dos } \\
\text { autores e periódicos }\end{array}$} & a) análise da rede de coautores em produção científica \\
\hline & & b) análise da rede de colaboração entre paises \\
\hline & & c) análise da rede de palavras que mais se destacaram nos títulos dos artigos \\
\hline $\begin{array}{c}\text { Análise } \\
\text { de } \\
\text { Conteúdo }\end{array}$ & Análise qualitativa & $\begin{array}{l}\text { a) análise de conteúdo dos artigos publicados internacionalmente com maior } \\
\text { relevância científica sobre o tema. }\end{array}$ \\
\hline
\end{tabular}

Fonte: Adaptado de Pereira, Prado, Antonialli et al. (2017).

\section{Análise das Publicações em Journals}

O primeiro aspecto a ser analisado refere-se a série temporal e artigos publicados. A evolução do número de publicações de 1997 a 2017 é expressa no Gráfico 1.

Gráfico 1 - Distribuição da produção científica sobre corrupção no setor público entre os anos de 1997 a 2017.

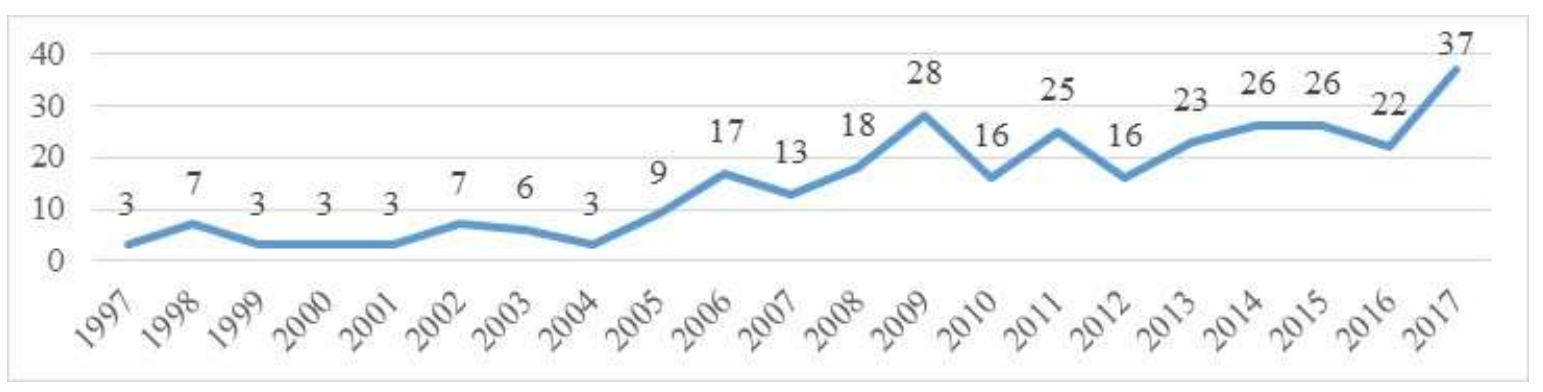

Fonte: Autores conforme resultados da busca do Scopus

O Gráfico 1 apresenta o número de publicações em cada ano. Destaca-se 2017 como o ano com maior número de artigos publicados sobre o tema. Os resultados evidenciam que nos últimos 5 anos foram publicados 134 artigos, em um total de 311 encontrados na pesquisa, ou seja, mais de $43 \%$ dos artigos sobre a temática foram publicados recentemente. Logo, observa-se que as publicações relacionadas a temática corrupção no setor público estão com uma tendência crescente, o que traz evidências 
de um maior interesse dos pesquisadores, nos últimos anos, em desenvolverem pesquisas referente ao assunto. Ao todo, 161 journals foram identificados com publicações relacionadas à corrupção na administração pública. No Gráfico 2 apresenta-se as dez revistas internacionais que mais publicaram sobre o tema.

Gráfico 2 - Journals em destaque em publicações internacionais sobre corrupção setor público 1997 a 2017.

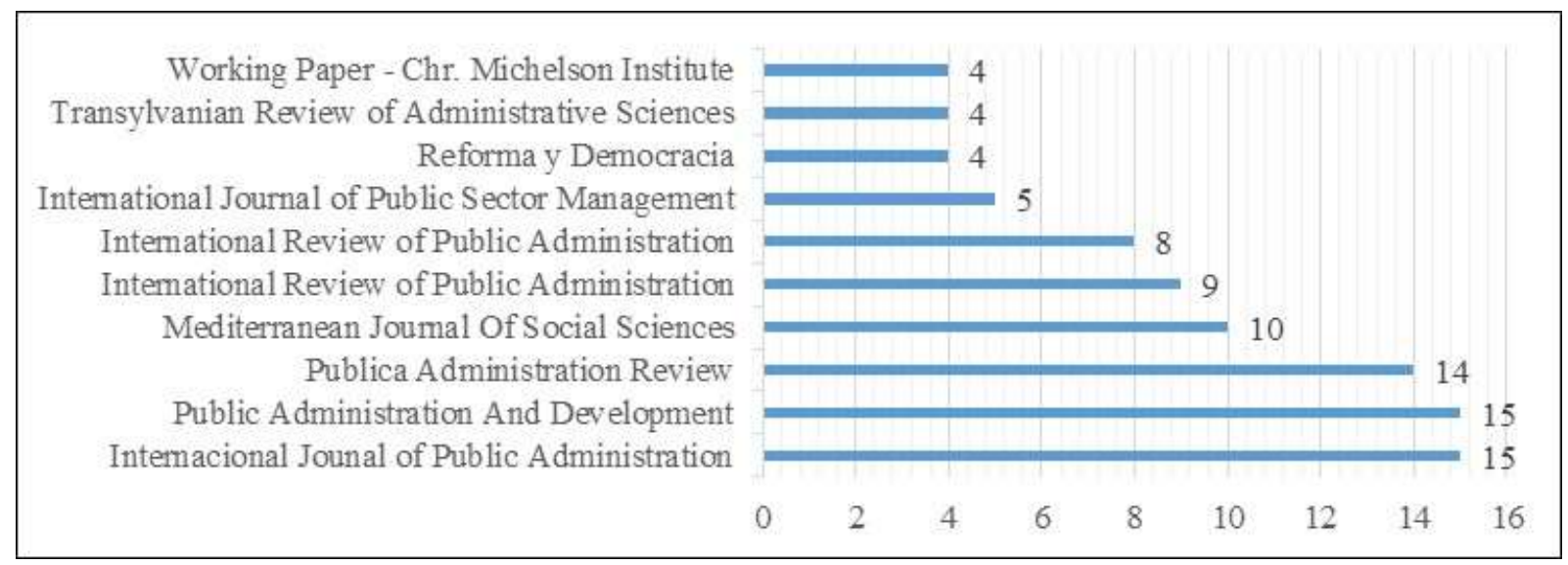

Fonte: Autores conforme resultados da busca do Scopus,

As principais fontes sobre corrupção no setor público são a International Journal Of Public Administration e Public Administration And Development, com 15 artigos publicados cada uma, seguido pela Publica Administration Review, com 14, e a Mediterranean Journal Of Social Sciences, com 10. Juntas essas quatro revistas foram responsáveis pela publicação de mais de $17 \%$ dos artigos no período. Nos últimos cinco anos a amostra de 311 artigos foi citada 2279 vezes, ou seja, uma média de 7,32 citações por publicação. Já os 10 artigos mais citados possuem 740 citações ao todo, perfazendo uma média de 74 citações por artigo (Tabela 1). 
Tabela 1 - Principais artigos sobre corrução com maior número de citações no período 1997 a 2017.

\begin{tabular}{|c|c|c|c|c|c|c|c|c|c|}
\hline Artigos & $\begin{array}{c}\text { Ano } \\
\text { publicação } \\
\text { artigo }\end{array}$ & $<2014$ & 2014 & 2015 & 2016 & 2017 & 2018 & $\begin{array}{l}\text { Total } \\
\text { citações } \\
\text { recentes }\end{array}$ & $\begin{array}{l}\text { Total } \\
\text { citações } \\
\text { artigo }\end{array}$ \\
\hline $\begin{array}{l}\text { The Merit of Meritocratization: Politics, } \\
\text { Bureaucracy, and the Institutional Deterrents of } \\
\text { Corruption }\end{array}$ & 2012 & 9 & 13 & 8 & 18 & 15 & 1 & 54 & 63 \\
\hline $\begin{array}{l}\text { Public trust in government in Japan and South } \\
\text { Korea: Does the rise of critical citizens matter? }\end{array}$ & 2010 & 18 & 10 & 9 & 16 & 13 & 2 & 50 & 68 \\
\hline $\begin{array}{l}\text { Revisiting the practices of corporate social and } \\
\text { environmental disclosure in Bangladesh }\end{array}$ & 2009 & 29 & 18 & 6 & 10 & 12 & 1 & 47 & 76 \\
\hline $\begin{array}{l}\text { E-Government and anti-corruption: Empirical } \\
\text { analysis of international data }\end{array}$ & 2008 & 26 & 10 & 13 & 11 & 14 & 4 & 52 & 78 \\
\hline $\begin{array}{l}\text { The determinants of corruption in Italy: } \\
\text { Regional panel data analysis }\end{array}$ & 2007 & 23 & 13 & 17 & 7 & 9 & 3 & 49 & 72 \\
\hline $\begin{array}{l}\text { Perceptions of political corruption in Latin } \\
\text { American democracies }\end{array}$ & 2005 & 24 & 5 & 7 & 7 & 4 & 1 & 24 & 48 \\
\hline $\begin{array}{l}\text { Corruption: An alternative approach to its } \\
\text { definition and measurement }\end{array}$ & 2005 & 35 & 6 & 8 & 5 & 3 & 0 & 22 & 57 \\
\hline $\begin{array}{l}\text { Political institutions and developmental } \\
\text { governance in sub-Saharan Africa }\end{array}$ & 2004 & 31 & 5 & 2 & 5 & 3 & 1 & 16 & 47 \\
\hline Globalization and public administration & 1999 & 90 & 9 & 9 & 4 & 4 & 0 & 26 & 115 \\
\hline Corruption and development & 1998 & 93 & 4 & 6 & 3 & 9 & 1 & 22 & 116 \\
\hline Total de citações & & 378 & 93 & 85 & 86 & 86 & 14 & 362 & 740 \\
\hline
\end{tabular}

Fonte: Autores conforme resultados da busca do Scopus.

Apesar dos artigos Globalization and public Administration (1999) e o Corruption and development (1998) serem os dois mais citados nas últimas duas décadas, não estão entre os mais citados nos últimos cinco anos. Nesse período os dois artigos que tiveram mais destaque em número de citações foram o The Merit of Meritocratization: Politics, Bureaucracy, and the Institutional Deterrents of Corruption (2012) e o E-Government and anti-corruption: Empirical analysis of international data (2008), com 54 e 52 citações respectivamente. Destaca-se ainda que das 740 citações totais, dos 10 artigos mais citados, 362 citações ocorreram nos últimos cinco anos, ou seja, 48,91\% das citações dos artigos aconteceram recentemente. Na Figura 1 apresenta-se o resultado do método de nuvem de palavras aplicado ao texto do abstract dos 311 artigos. Essa técnica foi utilizada com o objetivo de verificar quais as palavras e temas centrais mais abordados nas pesquisas realizadas. Destaca-se que as palavras na figura são posicionadas aleatoriamente de forma que as mais frequentes aparecem maiores que as outras, demonstrando, assim, seu destaque nas pesquisas. 
Figura 1 - Nuvem de palavras referente aos abstracts dos artigos publicados sobre corrupção entre 1997 e 2017.

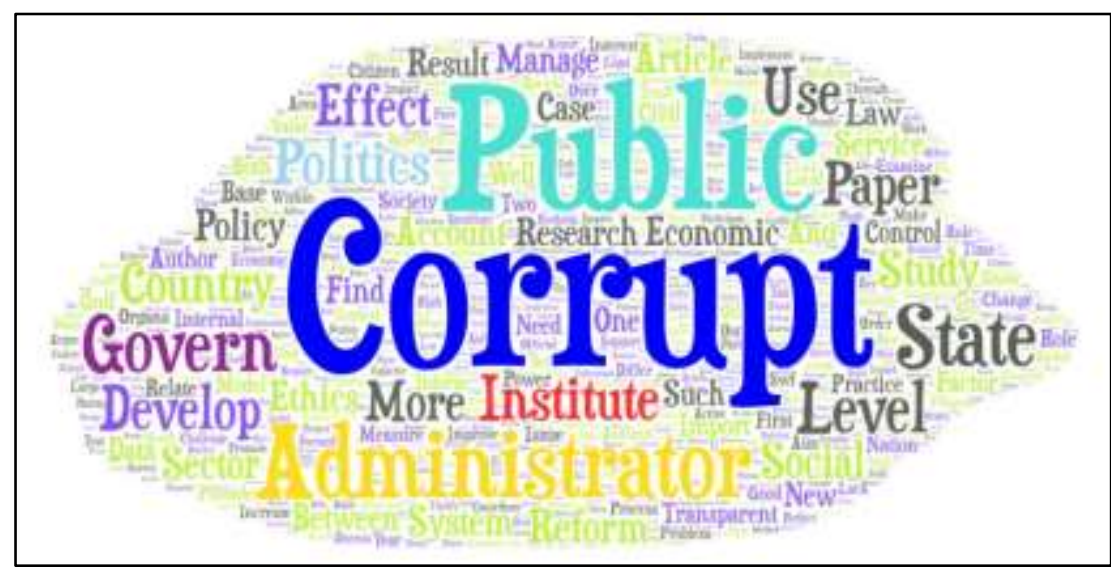

Fonte: Autores com base nos dados da pesquisa.

Pode-se evidenciar que as palavras que obtiveram maior destaque foram Corrupt (832), Public (775), Adminstrator (470), Govern (407), Politics (243) e Develop (240). Logo, o resultado parece indicar que as pesquisas de maior representatividade no meio acadêmico, e que se referem ao tema aqui estudado, tem direcionado seu foco para temas voltados a gestão corrupta de governos.

No Gráfico 3 apresenta-se os dez países principais em número de publicações internacionais sobre a temática. O Brasil não aparece na lista, pois consta apenas em $24^{\circ}$ lugar, com 04 (1,2\%) publicações, ou seja, o país ainda é inexpressivo na produção mundial sobre o tema.

Gráfico 3 - Países que se destacaram com publicações em periódicos internacionais sobre corrução no setor público en tre 1997 e 2017 .

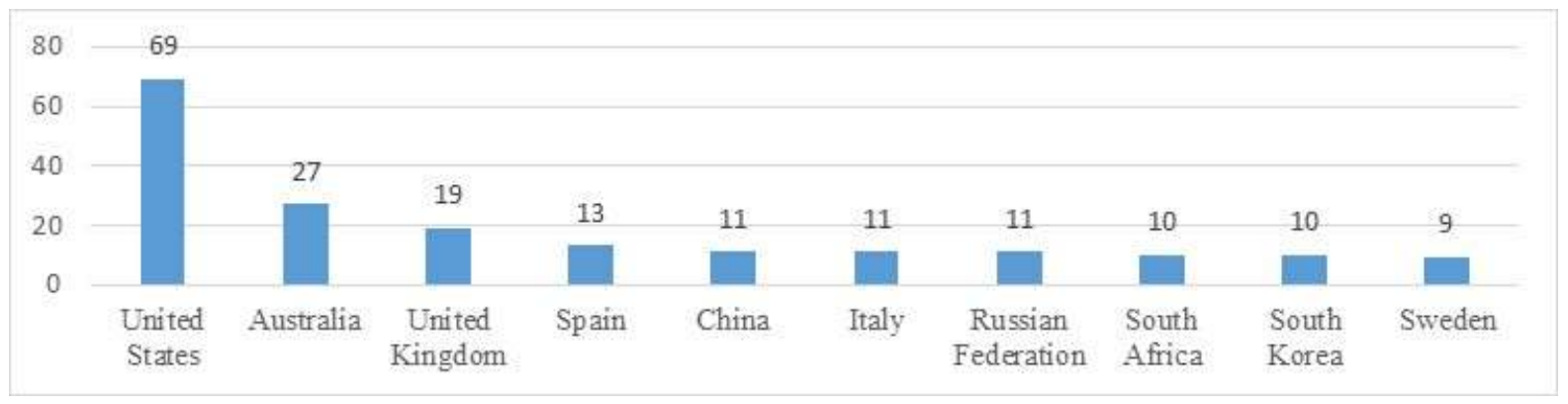

Fonte: Autores conforme resultados da busca do Scopus.

O país que mais publicou artigos sobre o tema corrupção na administração pública foi os Estados Unidos com 69 (22,1\%) artigos, seguido pela Austrália com 27 (8,6\%), e, na sequência, pelo Reino Unido com 19 (6,1\%). As evidências demonstram que esses três países geraram 36,8\%, ou seja, mais de $1 / 3$ de todas as publicações sobre o tema nas últimas duas décadas. No Gráfico 4, é realizada uma análise, com base nos dados do Scopus, para identificar o número de publicações e as instituições de filiação dos autores, indicando quais são as instituições internacionais mais produtivas sobre corrupção na administração pública nas últimas duas décadas. 
Gráfico 4 - Principais instituições em número de publicações sobre a temática nas últimas duas décadas.

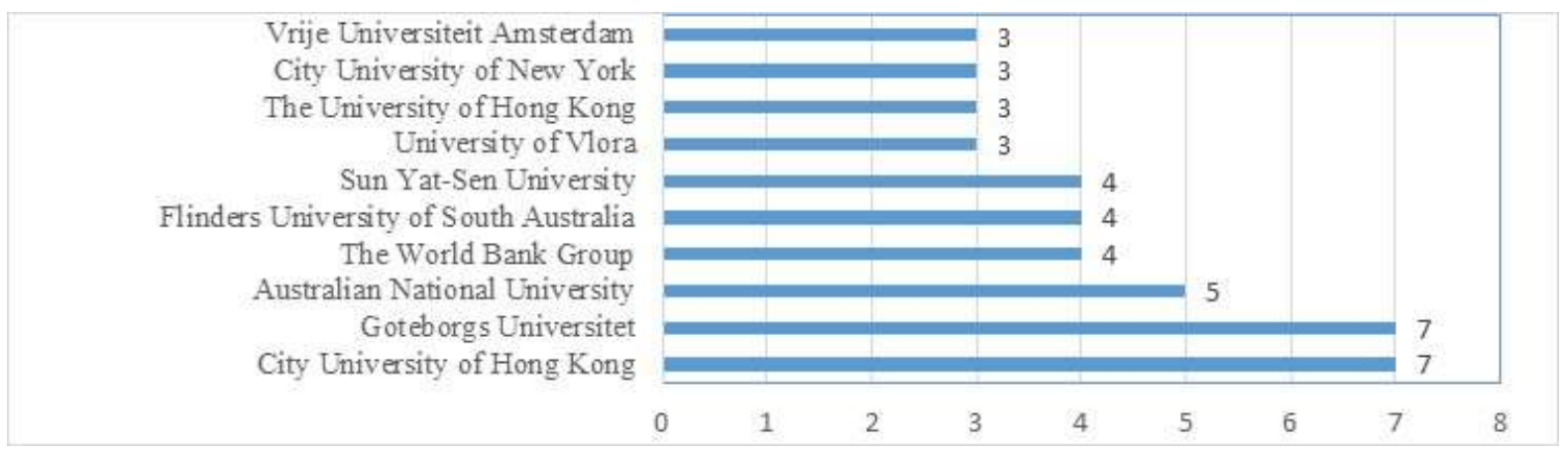

Fonte: Autores conforme resultados da busca do Scopus.

As universidades mais produtivas sobre o tema são a City University of Hong Kong e a Goteborgs Universitet com 07 artigos cada uma, ou seja, essas podem ser consideradas as principais universidades em nível de publicações de artigos científicos sobre corrupção no setor público. Percebe-se que a Austrália e China são os países que possuem o maior número de sede dentre as dez principais instituições que mais publicam sobre o tema. Contudo, o país com mais produção científica sobre a temática é os Estados Unidos, seguido da Austrália, e Reino Unido, conforme indicado no Gráfico 3. Nota-se que apesar da evidência produtiva dos autores filiados estarem em grande parte nas universidades da Austrália e China, estes países não se destacaram como mais produtivos. Sobre o número de autores que publicaram acerca da corrupção na administração pública, foram realizadas 158 codificações (referências), que envolve a quantidade total de autores nos artigos, considerando que há autores que produziram mais de um artigo (Gráfico 5).

Gráfico 5 - Principais autores em número de publicações sobre corrupção na administração pública 1997 a 2017

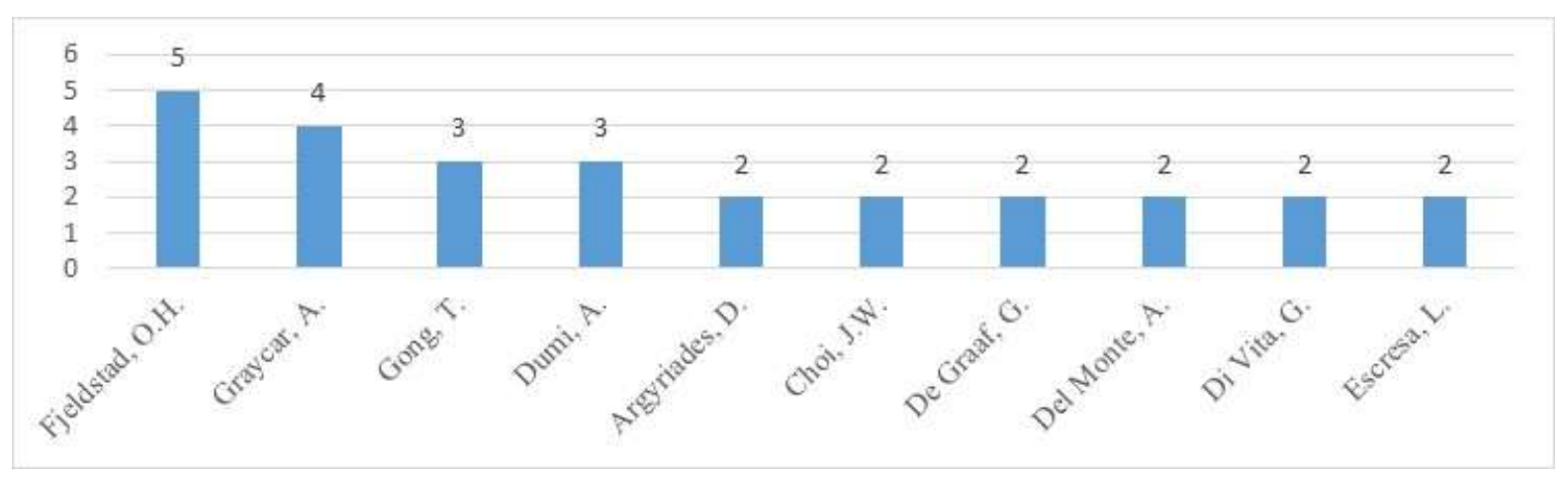

Fonte: Autores conforme resultados da busca do Scopus.

Os dez autores que mais publicaram sobre o tema totalizaram 27 artigos publicados. A média de publicação desses autores foi de 2,7. Constatou-se que Fjeldstad, Odd Helge (Estados Unidos) foi o autor que mais publicou sobre o tema com 5 artigos, os quais foram citados por 434 outros trabalhos. Em segundo lugar está Graycar, Adam (Austrália) com 4 artigos, os quais foram citados por 83 trabalhos. Em seguida tem-se Gong, Ting (China) e Dumi, Alba Robert (Albania) empatados com 03 artigos publicados. Os demais 06 autores todos publicaram 02 artigos sobre o tema. Os dois principais autores em número de artigos publicados são dos dois países que mais se destacam em publicações sobre o tema, Estados Unidos e Austrália respectivamente. 


\section{Análise das Redes de Cooperação}

Essa etapa teve como objetivo identificar quais os padrões de relacionamento e cooperação em produção científica desenvolvida pelos autores e países sobre a corrupção no setor público. Além disso, também buscou-se identificar através das redes quais as palavras tiveram mais destaque nos títulos dos artigos sobre a temática. As redes foram elaboradas com a utilização do software VOSviewer.As informações apresentadas na Figura 2 indicam a coautoria entre pesquisadores da amostra, sobre corrupção na administração pública, publicados em periódicos internacionais, compreendidos entre os anos de 1997 e 2017.

Figura 2 - Redes de coautorias em produção cientifica desenvolvidas entre 1997 e 2017 sobre corrupção.

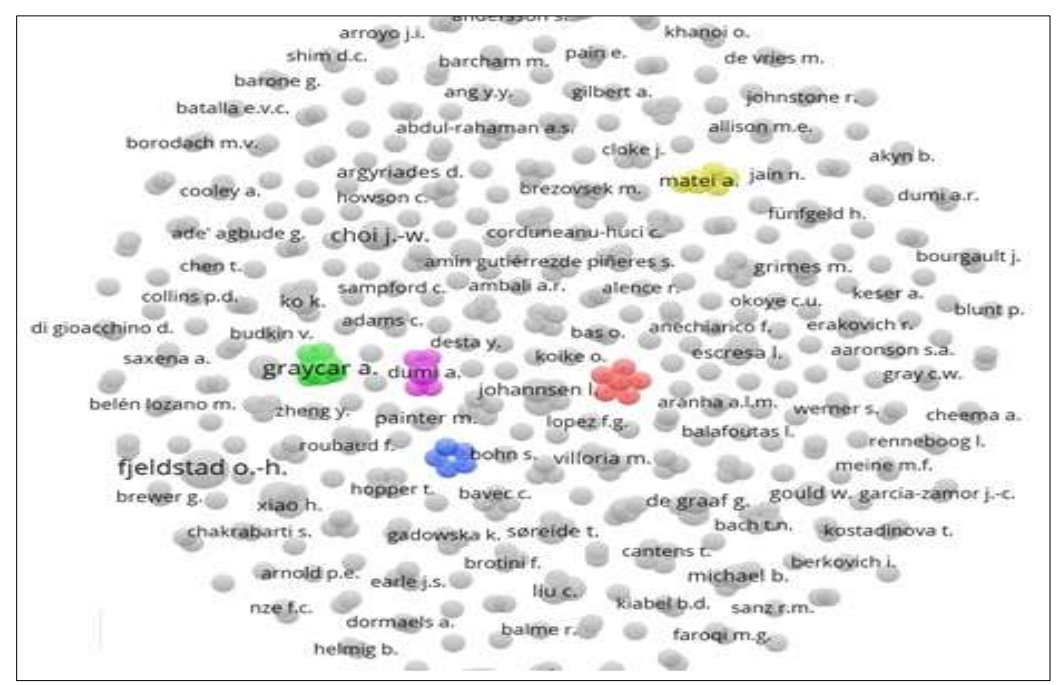

Fonte: Autores com dados da pesquisa.

A maioria os pesquisadores apresentam pequenas redes de cooperação em produção científica. Com apenas dois autores obteve-se 80 clusters, com três autores, 32 clusters e com quatro autores, 11 clusters. Levando em consideração que foram identificados 479 autores na amostra de 311 artigos, os resultados parecem indicar que existe um baixo interesse dos pesquisadores em realizar pesquisas em cooperação com diversos autores. Isso pode ser evidenciado pelo baixo número de clusters que possuem no mínimo cinco ligações entre autores, os quais estão destacados na Figura 2 de forma colorida. Para melhor visualizar os principais autores que desenvolvem pesquisa em cooperação apresentam-se os cinco clusters na Figura 3.

Figura 3 - Rede dos clusters que se destacaram na colaboração em pesquisas sobre corrupção no setor público.

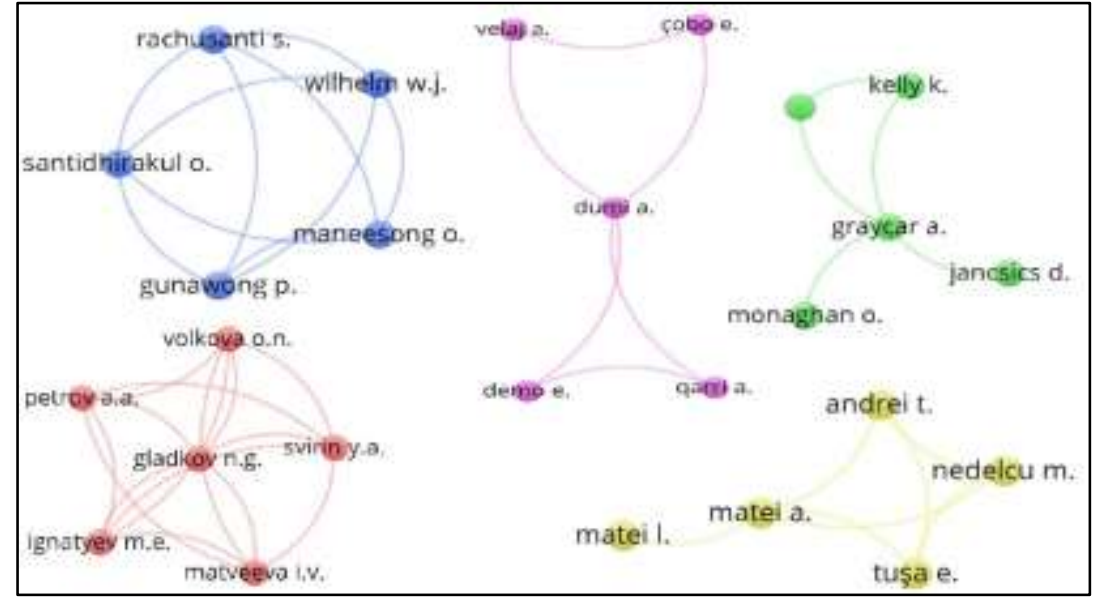

Fonte: Autores com dados da pesquisa. 
O cluster em destaque apresenta 5 ligações entre eles (vermelho) com maior força de associação. Entretanto, evidenciase que essa associação ocorre em apenas uma publicação. Já o autor Graycar, A. possui 2 artigos publicados e 4 ligações de coautorias, o que denota a maior rede de cooperação no desenvolvimento de pesquisas sobre corrupção na administração pública, porém o cluster (verde) tem menor força de associação decorrente de não ocorrer associação entre todos os autores deste cluster, como acontece no primeiro. $\mathrm{O}$ terceiro cluster (azul) é formado pela relação de 5 autores com apenas um artigo interligando-os. O quarto cluster (roxo) é formado pela associação em torno do autor Dumi, A., o qual apresenta duas publicações na temática com diferentes autores. Por fim, verifica-se na Figura 3 que o quinto cluster (amarelo) é formado pela associação das pesquisas do autor Matei, A. que apresenta força de associação 4. Esta força é decorrente da associação de 1 artigo publicado com Matei, L e 1 artigo com outros três autores, Tusa, E., Andrei, T. e Nedelcu, M.

Em seguida realizou-se a análise das redes de colaboração referente aos país de origem dos autores. Destaca-se que a rede de colaboração é formada pelos países que apresentam pelo menos duas ligações (Figura 4).

Figura 4 - Redes de cooperação entre países que mais se destacaram em publicações sobre corrupção no setor público de 1997 a 2017.

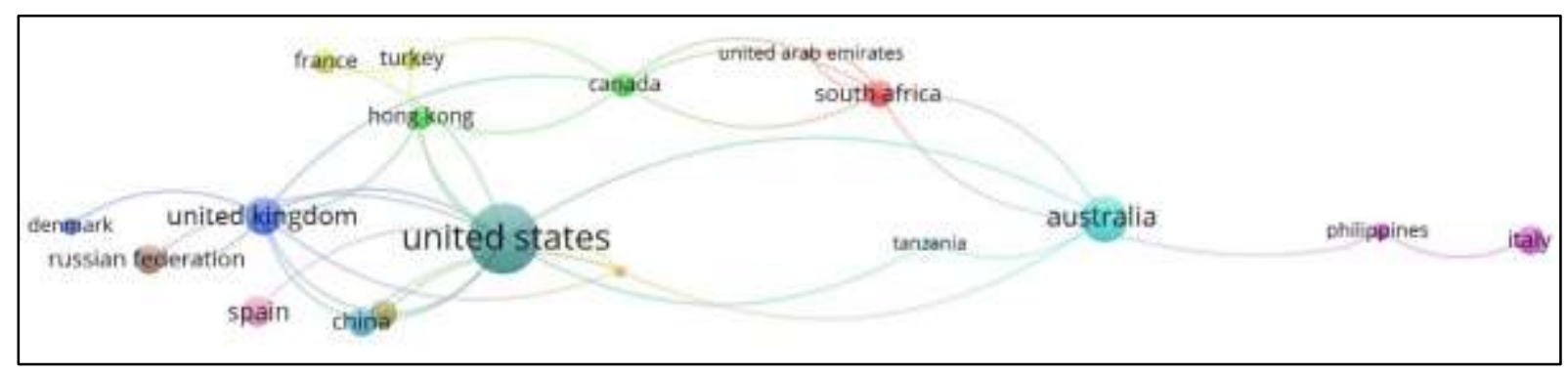

Fonte: Elaborado pelos autores com dados da pesquisa.

Os resultados indicam que os Estados Unidos é o país que mais realiza pesquisas sobre corrupção no setor público em cooperação com pesquisadores de outros países. Em segundo lugar aparece a Austrália, seguido pelo Reino Unido em terceiro. Logo, esses podem ser considerados os três principais países em nível de produção científica em cooperação com pesquisadores de outros lugares.

\section{Caracterização de Algumas das Publicações mais Citadas}

Entende-se que o número de citações de um artigo é um fator de impacto no meio científico. Logo, esse pode ser considerado um ponto relevante para destacar os principais trabalhos da literatura, uma vez que são de influência para o desenvolvimento da área em questão, visto que os pesquisadores estão se embasando em uma mesma fonte de informação para contribuir para os estudos da área. Desta forma, é apresentado no Quadro 3 um breve resumo dos dez artigos mais citados sobre a temática desta pesquisa. 
Quadro 3 - Análise do objetivo, objeto de estudo e resultados dos 10 artigos mais citados.

\begin{tabular}{|c|c|c|c|c|c|}
\hline Artigo & CT & Objetivo & Método & $\begin{array}{l}\text { Objeto de } \\
\text { Estudo }\end{array}$ & Resultados \\
\hline $\begin{array}{l}\text { Farazmand, A. } \\
\text { Globalization and } \\
\text { public } \\
\text { administration } \\
(1999)\end{array}$ & 116 & $\begin{array}{l}\text { Identificar as mudanças } \\
\text { geradas na administração } \\
\text { pública em prol da } \\
\text { globalização corporativa e } \\
\text { seus efeitos na } \\
\text { Administração pública. }\end{array}$ & Revisão teórica & $\begin{array}{l}\text { A globalização e } \\
\text { as mudanças na } \\
\text { administração } \\
\text { pública }\end{array}$ & $\begin{array}{l}\text { São muitas as mudanças na administração } \\
\text { pública geradas pela globalização. A } \\
\text { globalização não acaba com o estado e a } \\
\text { administração pública, mas empurra a } \\
\text { mesma para um aumento da privatização, } \\
\text { que, por consequência, promove maiores } \\
\text { oportunidades de corrupção, a qual } \\
\text { transforma recursos sociais em atividades } \\
\text { ilegais, imorais e improdutivas. }\end{array}$ \\
\hline $\begin{array}{l}\text { Gray, C.W., } \\
\text { Kaufmann, D. } \\
\text { Corruption and } \\
\text { development } \\
(1998)\end{array}$ & 115 & $\begin{array}{l}\text { Quais são as principais } \\
\text { causas e custos de } \\
\text { corrupção? Este artigo } \\
\text { examina essas perguntas e } \\
\text { sugere formas específicas } \\
\text { de melhorar esforços } \\
\text { anticorrupção r em } \\
\text { desenvolvimento } \\
\text { transição economias. }\end{array}$ & Quantitativo & $\begin{array}{l}\text { Custo financeiro } \\
\text { da corrupção. } \\
\text { Uma análise em } \\
146 \text { países }\end{array}$ & $\begin{array}{l}\text { Pesquisas indicam que o } \begin{array}{c}\text { impacto } \\
\text { econômico da corrupção cresceu }\end{array} \\
\text { significativamente nos últimos anos. Isso } \\
\text { leva, em geral, às seguintes conclusões: • O } \\
\text { suborno é generalizado, mas há variações } \\
\text { significativas através e dentro regiões. } \bullet \text { O } \\
\text { suborno aumenta os custos de transação e } \\
\text { incerteza em uma economia. } \text { S Suborno } \\
\text { geralmente leva a ineficiência resultados } \\
\text { econômicos. • A corrupção mina o estado e } \\
\text { sua legitimidade. }\end{array}$ \\
\hline
\end{tabular}

Shim, D.C., Eom,
T.H. Government and anti-corruption:

Empirical analysis of international data (2008)
Demonstrar que o governo eletrônico é uma 78 ferramenta eficaz para reduzir a corrupção, promovendo a boa governança.

\section{Quantitativo Governo \\ Eletrônico \\ O governo eletrônico tem um impacto consistentemente positivo na redução da corrupção na administração pública.}

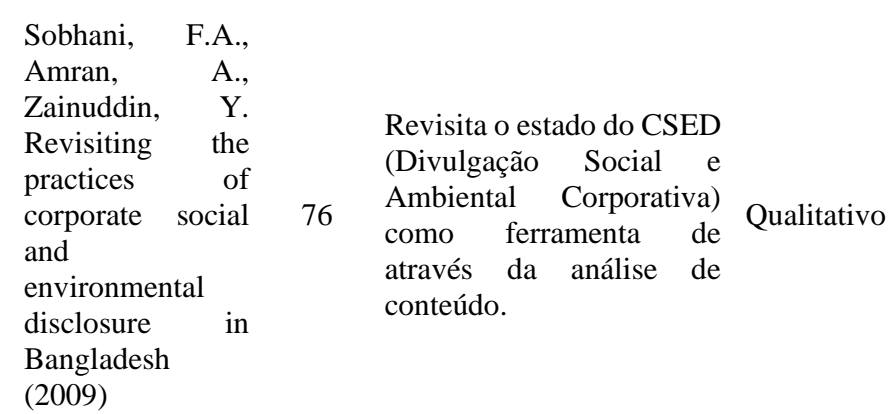

Del Monte, A., Papagni, E. The determinants of corruption in Italy: Regional panel data analysis (2007)

Kim, S. Public trust in government in Japan and South Korea: Does the rise of critical citizens matter? (2010)

Dahlström, $\mathrm{C}$ Lapuente, V., Teorell, J. The Merit of Meritocratization Politics,
Investiga os determinantes de corrupção na Itália no

72 período 1963-2001 usando estatísticas sobre crimes contra a administração pública a nível regional.

Verificar o desempenho do governo, no empoderamento dos cidadãos e a satisfação

68 com os valores de auto Quantitativo expressão associada à confiança pública no governo do Japão e da Coreia do Sul.

Analisar um conjunto de dados sobre a burocracia,

63 características e seus Quantitativo 52 países efeitos sobre a corrupção em cinquenta e dois países.
O governo do Bangladesh declara guerra contra a corrupção e empreende medidas pragmáticas na tentativa de garantir a boa governança das empresas no país. A estudo demonstra que o nível de divulgação de 100 empresas de informações melhorou nos últimos 10 anos. Bangladesh Todas as empresas da amostra $(\mathrm{n}=100)$ revelam pelo menos item de divulgação sobre questões de recursos humanos. No entanto, de uma perspectiva global o nível e a extensão da divulgação ainda são bastante escassos.

Estimativas mostram que as variáveis econômicas (consumo do governo, nível de desenvolvimento), influências culturais e Quantitativo Governo Italiano política (concentração partidária, presença de organizações voluntárias, absenteísmo nas eleições nacionais) afetam corrupção na Itália.

Este estudo identifica que o desempenho do governo na economia, o controle da corrupção política, a qualidade dos serviços

Governo Japão e públicos, o crime, e a atenção à Correia do Sul contribuição do cidadão, está significativamente associada à ampla confiança pública no governo tanto no Japão quanto no Sul Coréia.

Certos fatores burocráticos,
particularmente o recrutamento meritocrático, reduzem a corrupção. Já outros fatores burocráticos supostamente relevantes, como os salários competitivos dos funcionários públicos, a estabilidade na 


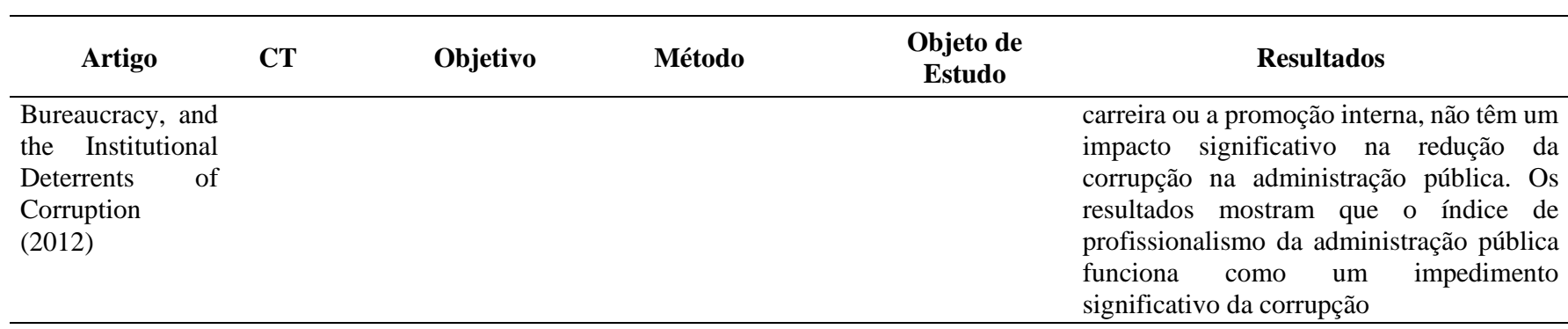

\begin{tabular}{|c|c|c|c|c|c|c|}
\hline $\begin{array}{l}\text { Kurer, } \\
\text { Corruption: An } \\
\text { alternative } \\
\text { approach to its } \\
\text { definition and } \\
\text { measurement } \\
(2005)\end{array}$ & 57 & $\begin{array}{l}\text { Avaliar e desenvolver uma } \\
\text { discussão sobre a definição } \\
\text { de corrupção. }\end{array}$ & Revisão teórica & $\begin{array}{l}\text { Diferentes } \\
\text { definiçõos } \\
\text { corrupção }\end{array}$ & de & $\begin{array}{l}\text { Existe um paradoxo de que, embora o termo } \\
\text { "corrupção" seja prontamente entendido e } \\
\text { aplicado em todos os lugares, dificilmente } \\
\text { haverá um mesmo entendimento sobre a } \\
\text { fronteira entre um ato corrupto e o não- } \\
\text { corrupto. }\end{array}$ \\
\hline
\end{tabular}

Canache, D., Allison, M.E. Perceptions of political corruption in Latin American democracies (2005)

Identificar o nível de 48 consciência dos latinoamericanos sobre o grau de corrupção em seus países.

Quantitativo
Países latino- O estudo conclui que os latino-americanos americanos são bastante conscientes da gravidade da corrupção nos seus países.

\begin{tabular}{|c|c|c|c|}
\hline $\begin{array}{l}\text { Alence, R. } \\
\text { Political } \\
\text { institutions and } \\
\text { developmental } \\
\text { governance in } \\
\text { sub-Saharan } \\
\text { Africa (2004) }\end{array}$ & 47 & $\begin{array}{l}\text { Analisar o impacto das } \\
\text { instituições políticas na } \\
\text { qualidade da governança } \\
\text { em uma amostra de } 38 \\
\text { países da África } \\
\text { subsaariana. }\end{array}$ & Quantitativo \\
\hline
\end{tabular}

A principal conclusão é que uma combinação de contestação democrática e restrições institucionais sobre a autoridade executiva discricionária dos governos melhora a governança qualidade que por consequência traz a uma menor corrupção. 38 países África As instituições mais democráticas estão subsaariana As instituições mais democráticas estão
melhorando os estados africanos e desempenhando seu papel como como agentes de desenvolvimento. Ao fazer governos politicamente mais responsáveis, parecem desencorajar o abuso do uso de recursos públicos para ganho privado.

Nota: CT = Número de citações. Fonte: Autores.

O trabalho de Farazmand (1999), com 116 citações, apresenta uma análise das mudanças geradas na administração pública pela globalização corporativa. Discute a globalização e suas implicações para a administração pública. Analisa os diferentes significados e perspectivas da globalização, das causas, consequências e suas implicações para sociedade, governança e administração pública. Aborda os impactos positivos tal como continuidade e persistência do estado e a administração pública, mas também os negativos como ameaça à democracia e comunidade, aumentando a corrupção e empoderamento da elite. Conclui que a globalização tem proporcionado um aumento no número de privatizações, que, por sua vez, promove maiores oportunidades de corrupção, complementa ainda, que a corrupção transformou recursos sociais em atividades ilegais, imorais e improdutivas.

O trabalho de Kaufmann e. Gray (1998, com 115 citações, destaca as principais causas e custos da corrupção. Para eles a corrupção é endêmica em todo lugar, os custos da corrupção são proibitivamente alto, há muitas evidências de que os custos econômicos da corrupção são enormes, os níveis de corrupção variam amplamente entre os países, controlar a corrupção é viável, e estratégias para lidar com a corrupção precisam prestar mais atenção às suas causas raízes. Como principal resultado tem-se a evidência de que o impacto econômico da corrupção cresceu significativamente nos últimos anos. Isso leva, em geral, a algumas conclusões como: • O suborno é generalizado, mas há variações significativas através e dentro regiões. • O suborno aumenta os 
custos de transação e incerteza em uma economia. • Suborno geralmente leva a ineficiência resultados econômicos. • A corrupção mina o estado e sua legitimidade.

O trabalho de Shim eEom (2008), com 78 citações, demonstra que o governo eletrônico é uma ferramenta eficaz para reduzir a corrupção, promovendo a boa governança. A principal questão de pesquisa é verificar se o governo eletrônico pode ser uma importante medida para conter comportamentos corruptos. Os autores destacam que na literatura existem duas abordagens distintas de governo eletrônico: a) governo eletrônico que controla comportamentos corruptos aumentando a eficácia de controle interno e gerencial, e b) a participação eletrônica que restringe a corrupção, aumentando a transparência do governo e a responsabilidade. As análises estatísticas, com dados de 146, revelam que o governo eletrônico apresenta uma relação positiva com a redução da corrupção.

\section{Considerações Finais}

O estudo buscou identificar o panorama das publicações de artigos científicos em periódicos internacionais que tratam sobre corrupção no setor público. O período de análise foi de 1997 até 2017 e utilizou-se como referência os artigos disponíveis na base de dados Scopus. Desenvolveu-se um estudo bibliométrico com a pretensão de conhecer qual o cenário quanto ao número de publicações sobre corrupção na administração pública com relação ao período, periódicos e instituições e países que mais publicam, bem como identificar o que mais se pública em relação a temática em nível mundial. A pesquisa contribuiu para evidenciar um panorama dos trabalhos internacionais mais relevantes sobre corrupção no setor público e também os principais autores, periódicos, países e a rede de relações entre as pesquisas e pesquisadores da área presentes na base de dados Scopus (Elsevier).

Fica claro que as publicações internacionais relacionadas a temática corrupção no setor público estão com uma tendência crescente, pois o número de publicações relacionadas ao assunto tem aumentado nos últimos anos. Evidência disso são as publicações dos últimos 5 anos que chegaram a 134 artigos, ou seja, mais de 43\% do total de artigos publicados sobre a temática nas últimas duas décadas são recentes. Logo, isso parece evidenciar a existência de um maior interesse dos pesquisadores no desenvolvimento de pesquisas sobre o assunto. Destaca-se que o Brasil figura, na lista dos países com publicações, em uma posição ainda incipiente, ficando somente em $24^{\circ}$ lugar com apenas 04 artigos publicados, isso indica uma necessidade de um maior aprofundamento do assunto em âmbito nacional.

Acredita-se que na medida em que aumentam o número de casos de corrupção divulgados pela mídia, existe uma tendência para o aumento do interesse de pesquisadores em desenvolver pesquisas na temática. Como limitação da pesquisa considera-se a restrição de se utilizar apenas artigos, visto que com a ascensão da temática nos últimos anos. Para trabalhos futuros sugere-se abordar também livros e outros documentos científicos disponíveis bem como estender a pesquisa ampliando o número de bases utilizadas, não se atendo somente ao Scopus, mas, sim, utilizando outras plataformas de pesquisa.

\section{Referências}

Abramo, C. W. (2000). Relações entre índices de percepção de corrupção e outros indicadores em onze países da América Latina. In: SPECK, B. W. et al. (Org.) Os custos da corrupção. Cadernos Adenauer, 10, 47-62.

Abram O, C. W. (2005). A dificuldade de medir a corrupção. Novos Estudos, CEBRAB. 10, 33-37.

Araújo, W. T. et al. (2000). Meta-análise das dissertações do curso de mestrado ciência da informação UFPB: 1990-1999. Revista Informação e Sociedade: estudos, 10(1), 1-11.

Bräscher, M. \& Café, L.(2008) Organização da Informação ou Organização do Conhecimento? In: Encontro Nacional de Pesquisa em Ciência da Informação, 2008, São Paulo, Anais... ANCIB.

Brasil. Lei $\mathrm{n}^{\mathrm{o}} 12.846$, de $1^{\mathrm{o}}$ de agosto de 2013. Dispõe sobre a responsabilização administrativa e civil de pessoas jurídicas pela prática de atos contra a administração pública, nacional ou estrangeira, e dá outras providências. Diário Oficial da União, Poder Executivo, http://www.planalto.gov.br/ccivil_03/_ato2011-2014/2013/lei/112846.htm 
Brei, Z. A. (2016). Corrupção: dificuldades para definição e para um consenso. Revista de Administração Pública, $30(1), 64$ - 77.

Brol, M. (2016). Institutional determinants of corruption. Ekonomia i Prawo. Economics and Law, 15(1), 21-32.

Controladoria Geral da União. A Responsabilidade Social das Empresas no combate à corrupção. (2009). https://www.cgu.gov.br/Publicacoes/etica-eintegridade/arquivos/manualrespsocialempresas_baixa.pdf.

De Oliveira Costa, C. L., da Cunha, D. D. O., Bezerra, L. F., de Oliveira, F. L., do Vale Júnior, J. S., \& Junior, E. S. (2020). A corrupção no setor público brasileiro. Research, Society and Development, 9(10), e5939109056-e5939109056.

Dolan, K., Mckeown, B. \& Carlson, J. M. (1988). Popular conceptions of political corruption: implications for the empirical study of political ethics. Corruption and Reform, 3(1), 3-24.

Elsevier. About Scopus. (2018). https://www.elsevier.com/solutions/scopus.

Elsevier. Scopus. (2011). http://www.americalatina.elsevier.com/corporate/scopus.php.

Ferenhof, H. A. et al. (2014). Environmental management systems in small and medium-sized enterprises: an analysis and systematic review. Journal of cleaner production, 74, 44-53.

Herzfeld, T. \& Weiss, c. (2003). Corruption and legal (in) effectiveness: an empirical investigation. European Journal of Political Economy, 19(3), 621-632.

Kitchenham, B. (2004). Procedures for performing systematic reviews. Keele, UK, Keele University, 33(2004), 1-26.

Luciano, E. M., Magnagnagno, O. A. \& Wiedenhöft, G. C. (2017). Entendendo as causas da corrupção no brasil e o papel da ti na redução Da vulnerabilidade a brechas de corrupção. Anais XX SEMEAD Seminários em Administração, FEA USP, São Paulo.

Luciano, E. M., Wiedenhöft, G. C., \& Callegaro, S. (2019). Entendendo os fatores de combate à corrupção: proposta de um constructo de dissuasão à corrupção. Revista de Contabilidade e Organizações, n. temático Fraudes e Corrupção: o que Contabilidade e Organizações têm a dizer? 20 -30.

Nações Unidas. (2007). Convenção das Nações Unidas contra a Corrupção. Convenção das Nações Unidas contra a Corrupção. 1 - 68.

Nascimento, I. C. (2016). A Cultura Importa? a produção científica sobre a relação entre corrupção e cultura nacional. Anais do Congresso Brasileiro de Estudos Organizacionais, Porto Alegre.

Nobre, B. P., \& Cotomacci, G. (2020). A distinção entre corrupção passiva e caixa dois. Revista do Curso de Direito, 15(15), 151-179.

Pereira, M. M. O. et al. (2017). Eco Inovação: um estudo bibliométrico como proposta de mapeamento dos estudos sobre o tema nas bases Web of Science e Scopus (1978-2016). Anais, XIX Engema, FEA/USP, São Paulo.

Peters, J. G. \& Welch, S. (1978). Political Corruption in America: A Search for Definitions and a Theory, or If Political Corruption Is in the Mainstream of American Politics Why Is it Not in the Mainstream of American Politics Research? The American Political Science Review, $974-984$.

Prodanov, C. C. \& Freitas, E. C. (2013). Metodologia do trabalho científico: métodos e técnicas da pesquisa e do trabalho acadêmico. 2. ed. Novo Hamburgo: Feevale.

Quevedo-Silva, F. et al. (2016). Estudo Bibliométrico: Orientações sobre sua Aplicação. Revista Brasileira de Marketing, 15(2), $246-262$.

Ribeiro, H. V., Alves, L. G., Martins, A. F., Lenzi, E. K., \& Perc, M. (2018). The dynamical structure of political corruption networks. Journal of Complex Networks, 6(6), 989-1003.

Schlickmann, A., \& Bortoluzzi, S. C. (2020). Análise Bibliométrica e de Conteúdo sobre a Avaliação de Desempenho Organizacional no contexto da Contabilidade Gerencial. In $9^{\circ}$ Congresso UFSC de Controladoria e Finanças.

Sims, R. L., Gong, B. \& Ruppel, C. P. A contingency theory of corruption: The effect of human development and national culture. The Social Science Journal, $1,90-97$.

Srivastava, S. C., Teo, T. S. H. \& Devaraj, S. (2016). You Can't Bribe a Computer: Dealing with the Societal Challenge of Corruption Through ICT. Mis Quarterly, 40(2), 511-526.

Transparency International. (2018). Transparency International. https://www.transparency.org/

Treisman, D. (200). The causes of corruption: a cross-national study. Journal of Public Economics, 399-457.

Vergara, S. C. (2005). Métodos de pesquisa em administração. Atlas.

Zaganelli, J. C. \& Miranda, W. V. D. (2017). Marco Civil da internet e política pública de transparência: uma análise da e-democracia e do compliance público. Revista Brasileira de Políticas Públicas, Brasília, 7(3), 633-646. 